\title{
Robotic Automation Process - The next major revolution in terms of back office operations improvement
}

\author{
Sorin ANAGNOSTE \\ The Bucharest University of Economic Studies, Bucharest, Romania \\ sorin.anagnoste@fabiz.ase.ro
}

\begin{abstract}
Forced to provide results consistent results to shareholders the organizations turned to Robotic Process Automation (RPA) in order to tackle the following typical challenges they face: (1) Cost reduction, (2) Quality increase and (3) Faster processes. RPA is now considered the next big thing for the Shared Services Centers (SSC) and Business Process Outsourced (BPO) around the world, and especially in Central and Eastern Europe. In SSCs and BPOs the activities with the highest potential for automation are in finance, supply chain and in human resource departments. This means that the problems these business are facing are mostly related to high data entry volumes, high error rates, significant rework, numerous manual processes, multiple not-integrated legacy systems and high turnover due to repetitive/low value added activities. One advantage of RPA is that it can be trained by the users to undertake structured repeatable, computer based tasks interacting in the same time with multiple systems while performing complex decisions based on algorithms. By doing this, the robot can identify the exceptions for manual processing, remove idle times and keep logs of actions performed. Another advantage is that the automated solutions can work 24/7, it can be implemented fast, work with the existing architecture, cut data entry costs by up to $70 \%$ and perform at $30 \%$ of the cost of a full time employee, thus providing a quick and tangible return to organizations. For Romania, a key destination for SSCs and BPOs, this technology will make them more competitive, but also will lead to a creation of a series of high-paid jobs while eliminating the low-input jobs. The paper will analyze also the most important vendor providers of RPA solutions on the market and will provide specific case studies from different industries, thus helping future leaders and organizations taking better decisions.
\end{abstract}

Keywords: Robot Process Automation, RPA, Shared Service Centers, BPO, Automatization

\section{Introduction}

Once in a while there comes a technology that disrupts how things are "usually done" in a business. After the Industrial Revolution and the Manufacturing Revolution we are now assisting to the Robots Revolution. It is the next step after the internet, the Enterprise Resource Planning (ERP), Customer Relationship System (CRM), cloud computing etc., and is called Robotic Automation Process (RPA).

Forester Research, a market research company, estimated that the RPA market will reach $\$ 2.9$ billion by 2021 from $\$ 250$ million in 2016 (Le Clair, Cullen, King, 2017). What is more interesting, with more than 60,000 jobs working in industries that are target to RPA technology this can be a treat and an opportunity for Romania and its workforce.

\section{About RPA technology and its future}

Through RPA organizations can develop robots which will lead to automation of an extensive variety of back office and front office activities, bridging thus the organization and moving people to high-value added tasks. Among the most performed actions of the bots are: monitoring an event (e.g. emails received or documents saved in a specific folder), reading and extracts data from file (e.g. PDF files, from email), performs checks against a 
defined set of criteria (e.g. VAT, type of service, type of Purchase Order, etc.), logging securely in one or multiple programs (e.g. Customer Relationship Management, Enterprise Resource Systems, etc.), creating successfully documents in company's systems, making decisions based on predefined set of conditions (e.g. if the attachments of an email are in a format not agreed by the organization, than the robot can email back to the sender requesting the files to be submitted according to the organization's standard), sending confirmations (e.g. emails, messages, logs, etc.) (Wilcocks et al,,2015).

Thus, summarizing in Table 1 the main characteristics of RPA technology:

Table 1. Characteristics of Robot Process Automation

1. Trained by the users
2. Working with the client's user interface
3. Undertake structured, repeatable, computer based tasks
4. Works flawlessly with multiple systems
5. Works with different electronic formats (e.g. PFD, MS Excel etc)
6. Performs cheks and takes in consideration validations points according
to a predefined set ot rules
7. Identifies easily exceptions (either against a database, either based on a
specific condition inserted in the code)
8. Works $24 / 7$ and during the holidays and weekends
9. Logs are stored inside the program, but can be configured to be sent by
email at a specific point, date or frequency
10. Provides a case for introduction of analytics

Source: Authors' own research.

One of the big advantages of RPA solution is that it can be trained by the business users in a fraction of seconds/minutes without being necessary the intervention of external consultants implying significant costs. Because the RPA solution doesn't require a technical background for those designing the process, organizations can allocate people from different departments when establishing a Center of Excellence (Coe). Once the CoE is established the supervision of all robots and future projects or changes that existing robots need can be tackled in a Lean methodology, assuring that organization's performance is not disturbed.

Up to the moment there is no one RPA vendor service provider that can excel in everything. Each vendors has it strengths and weaknesses. The most important RPA players are: Automation Anywhere (USA), BluePrim (UK), UiPatch (Romania), RedWood (Netherlands), Workfusion (USA) and Openspan (USA) as seen in Figure 1: 


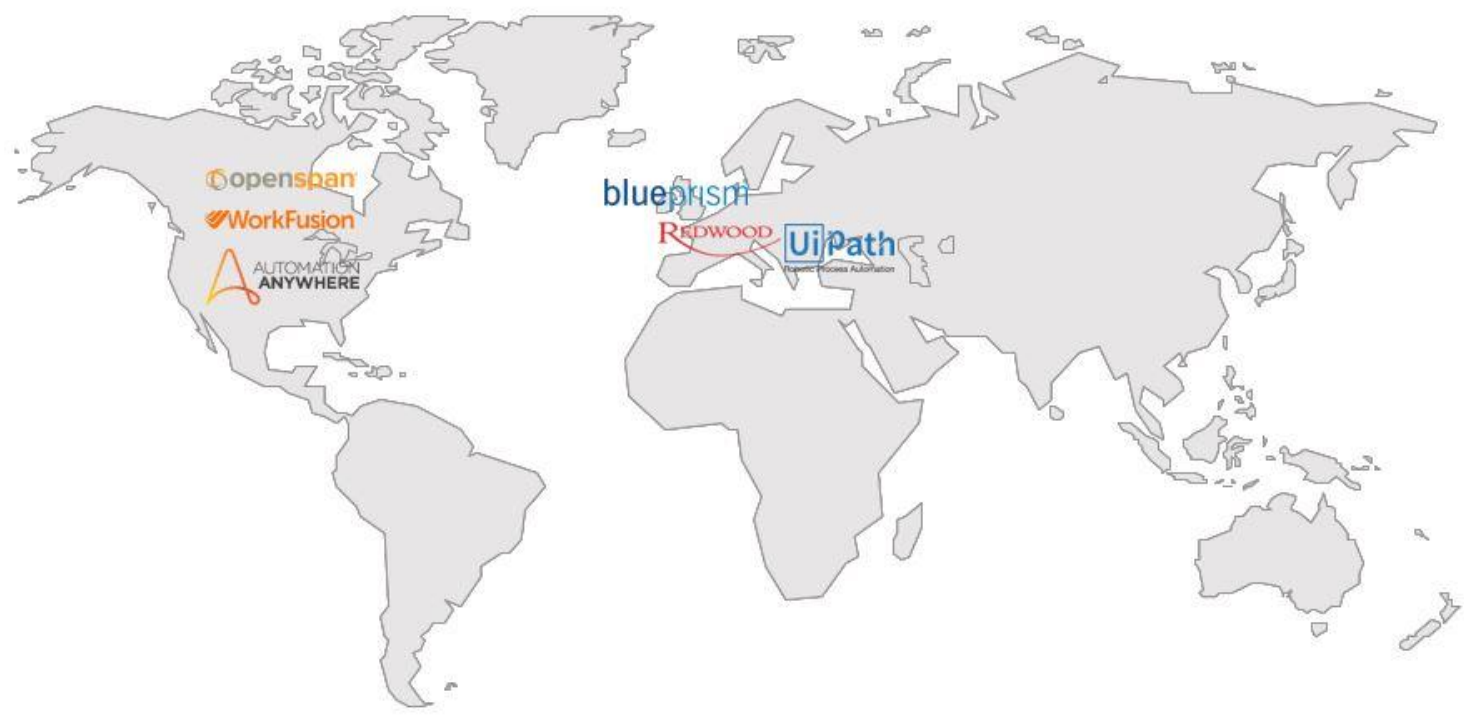

PICBE | 678

Figure 1. Leading RPA providers

Source: Authors' own research.

In the Everest Group Report (2017) the assessment the best RPA solutions available was made according to a (1) market impact and (2)) vision and capability. The resulted ranking can be seen in Figure 2:

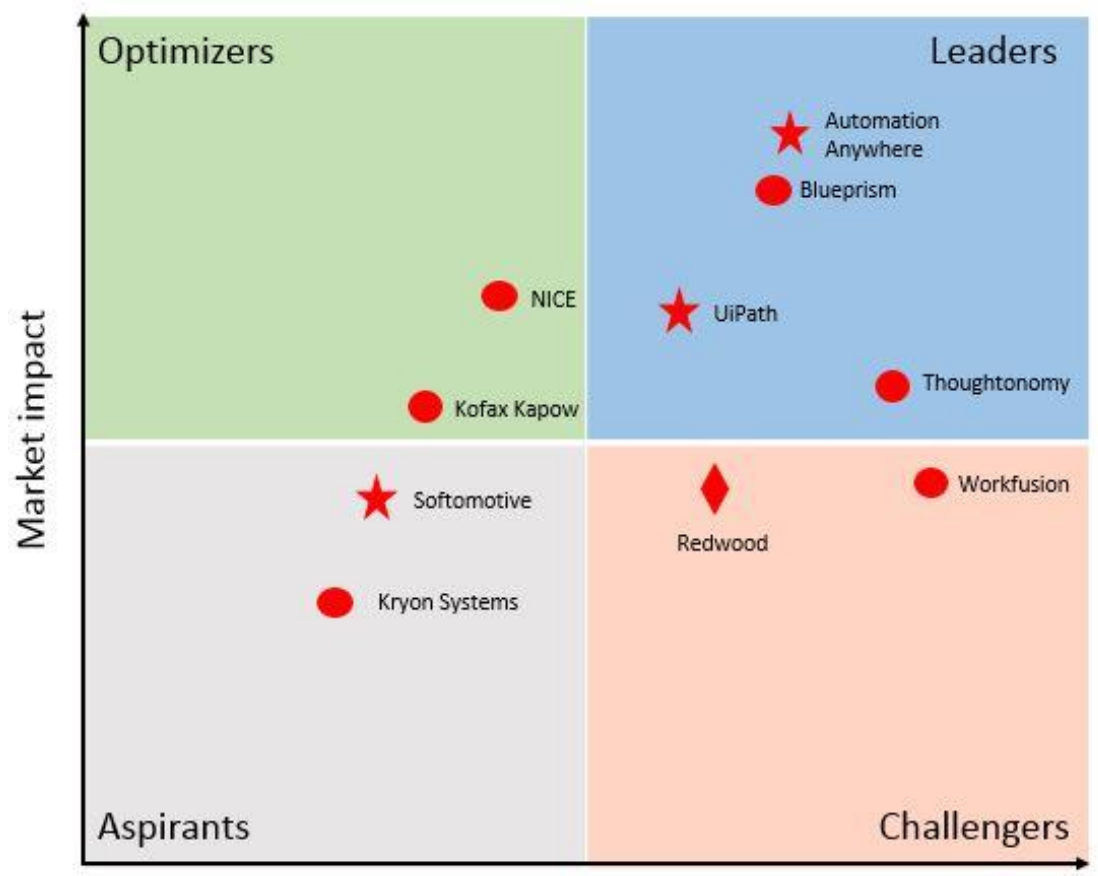

Vision and capabilities

Figure 2: Vendors scored using Everest's proprietary scoring methodology.

Source: https://go.forrester.com/.

As a result, Uipath (vendor from Romania) and Automation Anywhere (vendor from USA) are the star performers of the research. The most impressive year-on-year is Uipath which witnessed an impressive growth in terms of clients, revenue and human capital. The 
increase is also due to the right mix of pricing and strategic partnerships. Being present now on five continents with offices close to key clients offered the team a way to increase the share of larger clients in its portfolio, such as: BBC, J.P. Morgan, SAP, McDonalds, Vodafone, AXA to name a few.

Moreover, UiPath saw easily what clients want to do next with the RPA technology, so developed their core platform to include new functions and to enhance the cloud technologies.

As a result, the Everest Research Group (2017) mentions that new features were added: "process mapping, collaboration tool, configurable analytics, based on Elasticsearch Kibana and embedded help tool".

Because UiPath is a Romanian vendor and subject to the two case studies of this research the focus will be mainly on it. Uipath has three key parts to its RPA platform:

1) Uipath Studio - a flowchart-based visual process modelling tool

2) UiPath Orchestrator - a web-based management console, which helps the admin to manage the robots, offering though a clear image of what is running and what is each robots' status

3) UiPath Robot - robots designed in UiPath Studio, which run and are being managed through UiPath Orchestrator

Although the RPA vendor providers are offering a wide range of services like recording actions, task scheduler, collaboration tool, process mapping, audit trail, performance analytics, modularity and reusability the need for future improvement in the area of multi-tenancy, context awareness, adherence to supporting methodology (e.g. Six Sigma) there are still in need to be developed (please, consult Table 2):

Table 1. RPA service offerings

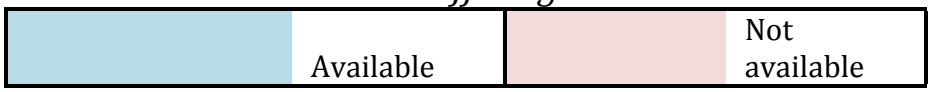

\begin{tabular}{|c|c|c|c|c|c|c|}
\hline $\begin{array}{l}\text { Options for } \\
\text { automation } \\
\text { creation }\end{array}$ & $\begin{array}{l}\text { Code for } \\
\text { actions }\end{array}$ & Record the actions & $\begin{array}{l}\text { Assemble } \\
\text { objects from } \\
\text { previous } \\
\text { automations } \\
\end{array}$ & $\begin{array}{l}\text { Visual } \\
\text { drag\&drop } \\
\text { development }\end{array}$ & $\begin{array}{l}\text { Machine- } \\
\text { learning } \\
\text { based }\end{array}$ & $\begin{array}{l}\text { Natural } \\
\text { Language } \\
\text { Processing }\end{array}$ \\
\hline $\begin{array}{l}\text { Deployment } \\
\text { options }\end{array}$ & $\begin{array}{l}\text { Client-hosted } \\
\text { on } \\
\text { desktop/laptop }\end{array}$ & $\begin{array}{l}\text { Client-hosted on } \\
\text { server }\end{array}$ & $\begin{array}{l}\text { Provider- } \\
\text { hosted, } \\
\text { multi- } \\
\text { instance }\end{array}$ & $\begin{array}{l}\text { Provider- } \\
\text { hosted, } \\
\text { single- } \\
\text { instance }\end{array}$ & $\begin{array}{l}\text { Partner- } \\
\text { hosted, } \\
\text { multi- } \\
\text { instance }\end{array}$ & On Cloud \\
\hline \multirow{5}{*}{$\begin{array}{l}\text { Key tool } \\
\text { features }\end{array}$} & $\begin{array}{l}\text { Pre-built } \\
\text { connectors } \\
\end{array}$ & $\begin{array}{l}\text { Role-based access } \\
\text { controls }\end{array}$ & $\begin{array}{l}\text { Task } \\
\text { scheduler } \\
\end{array}$ & $\begin{array}{l}\text { Collaboration } \\
\text { Tool } \\
\end{array}$ & \multicolumn{2}{|c|}{ Handling unstructured data } \\
\hline & $\begin{array}{l}\text { Support for } \\
\text { project } \\
\text { management }\end{array}$ & $\begin{array}{l}\text { Disaster } \\
\text { management }\end{array}$ & $\begin{array}{l}\text { Dynamic bot } \\
\text { scaling over } \\
\text { cloud }\end{array}$ & $\begin{array}{l}\text { Run-time } \\
\text { automation } \\
\text { management } \\
\text { and control } \\
\end{array}$ & \multicolumn{2}{|c|}{$\begin{array}{l}\text { MI and performance } \\
\text { analytics }\end{array}$} \\
\hline & $\begin{array}{l}\text { Backward } \\
\text { compatible }\end{array}$ & $\begin{array}{l}\text { Context } \\
\text { awareness }\end{array}$ & $\begin{array}{l}\text { Change } \\
\text { Management }\end{array}$ & $\begin{array}{l}\text { Adherence to } \\
\text { supporting } \\
\text { methodology } \\
\text { (6 Sigma) }\end{array}$ & \multicolumn{2}{|c|}{ Libraries of automation } \\
\hline & $\begin{array}{l}\text { Credential } \\
\text { vaults }\end{array}$ & Work queues & $\begin{array}{l}\text { Multi- } \\
\text { tenancy }\end{array}$ & $\begin{array}{l}\text { Inbuilt- } \\
\text { version } \\
\text { control }\end{array}$ & \multicolumn{2}{|c|}{ Modularity and reusability } \\
\hline & Rules engine & Process mapping & \multicolumn{4}{|l|}{ Audit trail } \\
\hline
\end{tabular}




\begin{tabular}{|l|l|l|l|l|l|l|} 
& & & Tool- & Consulting by \\
Support & $\begin{array}{l}\text { Training by } \\
\text { vendor }\end{array}$ & $\begin{array}{l}\text { Training by } \\
\text { partners/resellers }\end{array}$ & $\begin{array}{l}\text { Consulting } \\
\text { by vendor }\end{array}$ & $\begin{array}{l}\text { partners / } \\
\text { third parties }\end{array}$ & $\begin{array}{l}\text { User } \\
\text { community }\end{array}$ & $\begin{array}{l}\text { embedded } \\
\text { help }\end{array}$ \\
\hline
\end{tabular}

Source: https://go.forrester.com/.

Like already stated at the beginning of this research, the robot can run either on a physical machine or a virtual machine while working in the same time with all the client's legacy systems: ERP, web-based applications, cloud, Citrix, Java and mainframe applications. UiPath works with key players like Google, Microsoft and IBM in order to provide cognitive and machine learning capabilities when handling data.

RPA technology follows a pre-defined set of rules for any company willing to adopt it, as described by Everest Research Group:

1. Availability and quality of product features - the easiness of integrating the thirdparty applications at API level.

2. Deployment and support - robots can be hosted at client's premises or in the cloud, solution offered by the developer at competitive pricing

When it comes to support, UiPath is using either a team of trainers at client's premises, either MOOCs (Massive Open Online Courses) or through business partners (e.g. EY, Deloitte etc)

3. Buyer coverage - for UiPath the most important market at the moment is the US one, followed by UK and Continental America. The company opened offices in Bangalore and in Japan with the aim of securing additional growth from these markets.

4. Pricing model - Uipath is using the subscription-based licenses model, which includes also the maintenance. Implementation services are optional and the licenses are available per-user basis

5. Process coverage - most of the coverage is done in Finance \& Accounting, Procurement, Human Resources and IT departments.

In the report developed by Forrester Research institute called "Robotic Process Automation" (appeared in Q1 2017, in a 28-criteria evaluation of RPA providers, the institute declared the winners that are leading the pack: Automation Anywhere, Blueprism and UiPath (please see Figure 3):

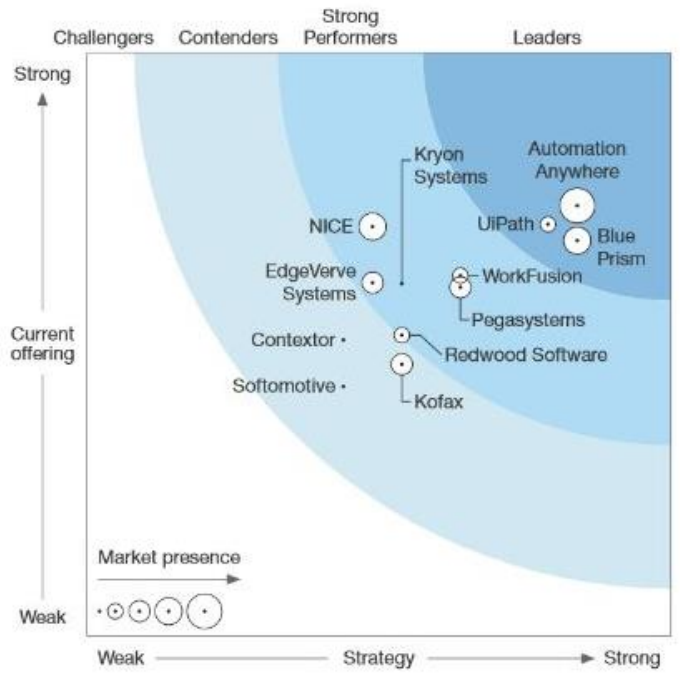

Figure 3. RPA evaluation according to Forrester Institute

Source: https://go.forrester.com/. 
The study validated the already discussed topics in this research:

1. Boost in productivity with minimal process change - because robots can replicate exactly what humans are doing

2. Impressive Return on Investment (ROI) - the cost of licensing a robot is between 3,000 EUR and 8,000 EUR annually, compared cu 30,000 EUR for a full-time employee (FTE). A robot can replace not one, but three FTEs and can work also in weekends and during the holidays, so the actual ROI is even more impressive

3. RPA is a "cheap" technology - there is a switch in business paradigm from having software implementation over the course of several years and millions of euros in spending to implementation in 4 to 6 weeks and no more than 80,000 EUR for a process.

Forrester Institute estimates that by the end of 2021 there will be 4 million robots in production (2017), and thus becoming an issue in terms of governance and management, which organizations and countries alike will look for proper solutions.

It is interesting to see how the future will look like for Uipath, a Romanian RPA vendor provider, which in 2017 ranked first in the technology category, according to Forrester.

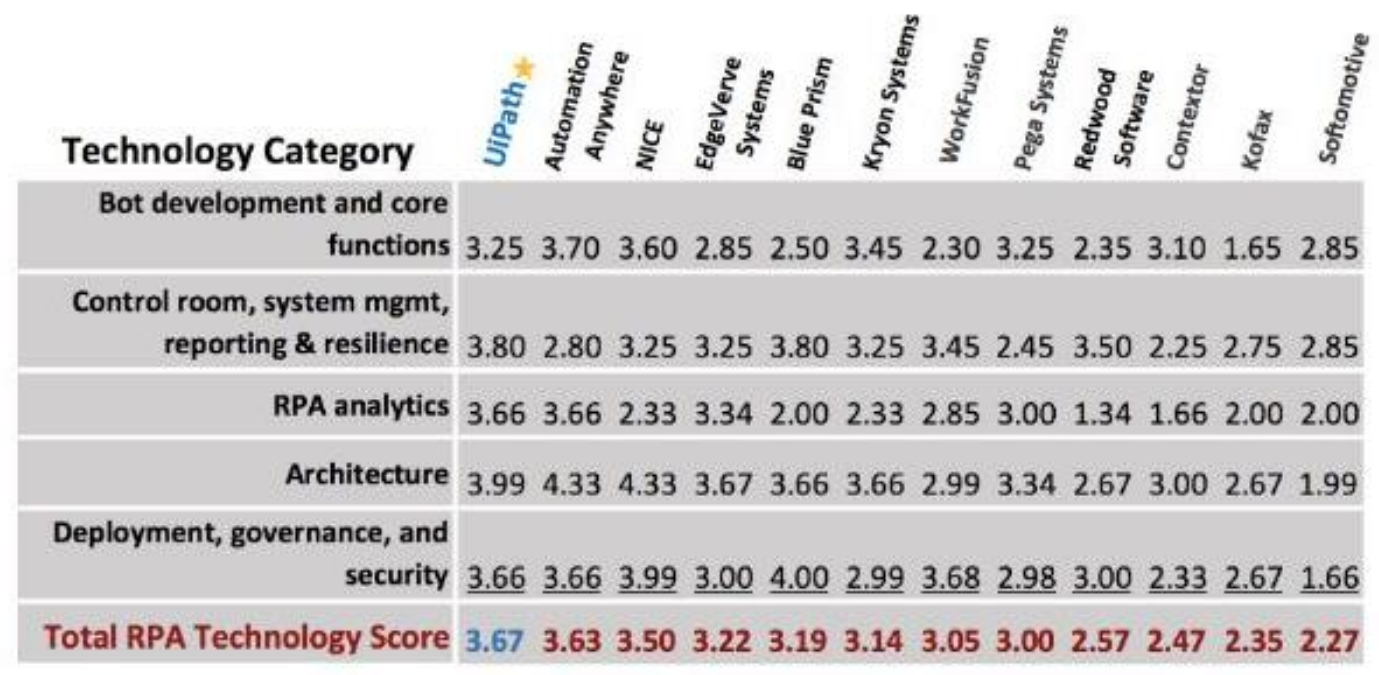

Figure 4. RPA vendors ranked by technology capabilities

Source: https://go.forrester.com/.

Going further into details the following areas is where RPA has the best yield (Willcocks et al., 2015):

1. Finance and Accounting - mostly in the following sub-departments: Sales order; Order to Cash (O2C); Collection; Procure to Pay (P2P); Incentive Claim; Record to Report (R2R); Supply Chain Vendor setup; Trend Tracking.

2. Human Resource services - mostly in the following sub-departments: Payroll; Benefits \& Compensation; Pay slips Management; Time and Attendance management; Recruiting and Onboarding; Education and Training; Compliance Reporting. 
3. Supply Chain - mostly in the following sub-departments: Work Order Management; Demand and Supply Planning; Quote, Invoice and Contract Management; Returns Processing; Freight Management.

4. IT services - mostly in the following sub-departments: Installation; FTP download; upload and back-up; Server application and monitoring; Synchronizing, Deleting and Emptying folders; File Management; Email processing; Batch processing.

\section{Impact on the Romanian workforce market}

According to Pascari (2016) and to annual report of the Association of Business Service Leaders in Romania (ABSL) also from 2016 resulted that there are more than 50,000 specialists working in Shared Service Centers and Business Process Outsourcing providing a wide pallet of services, from finance to procurement, from IT and Human Resources, in different languages: English, German, French, Spanish, Italian, Russian, Hungarian, Nordic languages and so on.

The main locations for these centers are the big cities which nurtured a positive business environment which is correlated with important universities: Bucharest, ClujNapoca, Timisoara, but also other small cities like Brasov, Pitesti, Craiova, Oradea etc. (please see Figure 5).

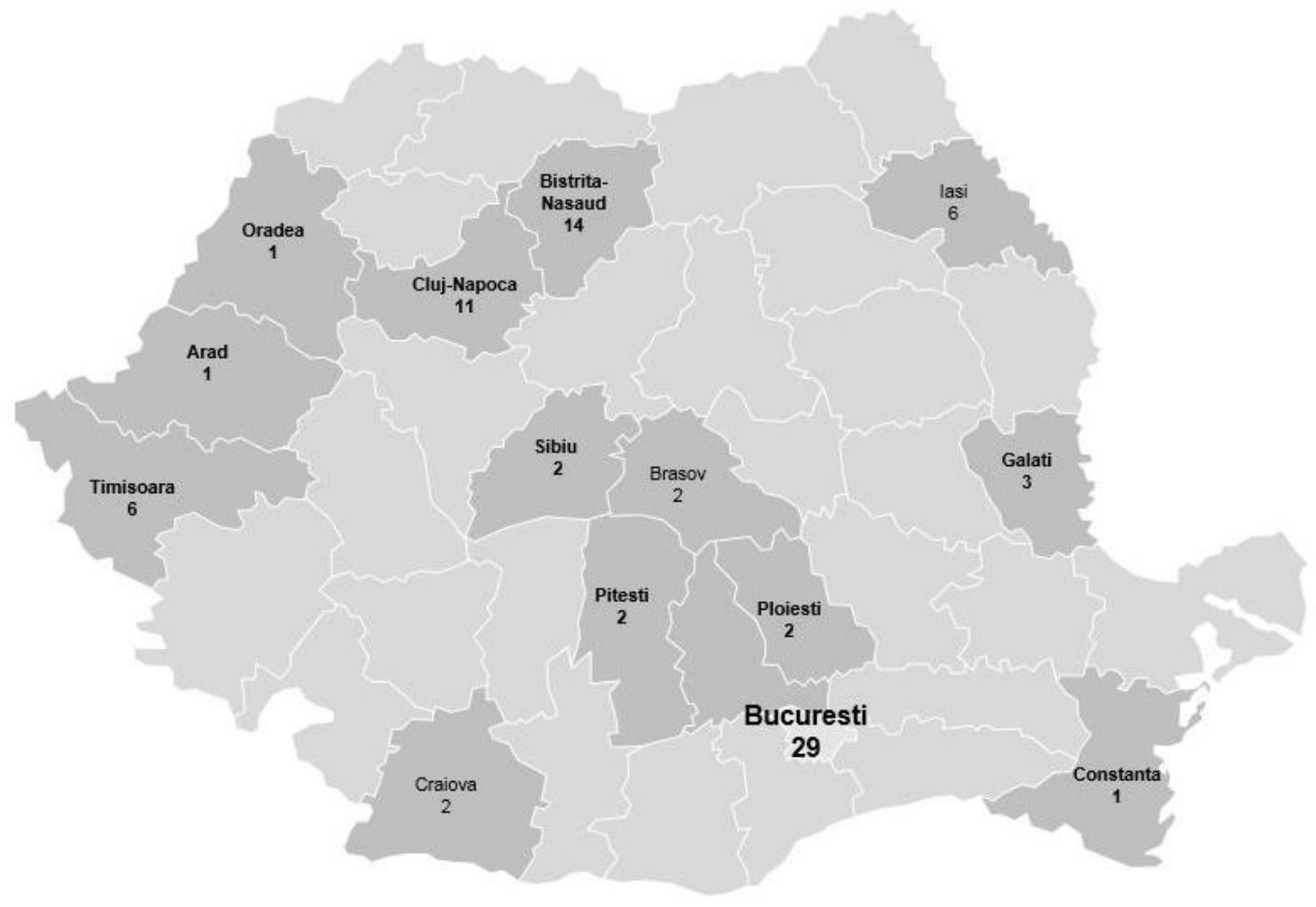

Figure 5. Romanian shared service centers and business process outsourcing companies

Source: http://www.absl.ro/.

On the employment structure by types of services provided by internal units the report shows that $18 \%$ are working in IT, $28 \%$ in Finance \& Accounting (F\&A), 14\% in Banking, Insurance, Financial services, 18\% in Customer Operations and the rest in HR, Supply Chain Management and other services. 
It's important to realize that at this moment up to $50 \%$ of the work performed by employees in financial services, customer operations, banking, insurance and human resources can be automated, so RPA can constitute an opportunity for improving efficiencies while making millions of savings yearly. According the industry reports the average salary (taxes included) is approximately 30,000 EUR/year/employee. With up to 30,000 employees having jobs at risk that can be automated we are speaking of savings of approx. 900 million EUR a year. Of course, not all the FTEs will be let go, but rather at least a good part of them will be moved to high-value added tasks. Also in the ABSL report it is mentioned that 19 out of 36 organizations providing these services have expansion plans. So here is a huge opportunity for organizations, for employees and for our country with a shrinking and aging population alike.

\section{Case studies}

\section{Introduction of RPA to a service provider company}

The need for RPA solutions was mentioned by the Human Resource (HR) department when making the year end letter promotions; which include among other the salary of that person in the previous financial year and the new salary of that person in the next financial year. Increases are based either on promotion (e.g. from Junior to Senior), either on performance (e.g. good, very good, excellent). So, more than one or two conditions to be taken in consideration.

In the past, one person from HR department was doing this activity for more than 500 employees and it was taking five working days. When the RPA team was introduced to this project they realized that what was done at that time by that FTE could be done by a robot much faster.

The team developed the robot according to Agile methodology, in Sprints; this helped the process owner to see the full-plan in advance and to check each time was a question.

RPA implementation has different timeframes, depending of what the client wants:

- Proof of concept (PoC) - performed to demonstrate the RPA capabilities on the clients' premises. Not all the exceptions are handled. This usually takes 3 to 5 weeks

- Initial Pilot - perform a RPA mission only for a part of the process in order to confirm that the business case is viable. This usually takes 6 to 8 weeks

- Scale pilot - performing RPA according to the developed business case. This can take 8 to 12 weeks.

In our case, because it was a simple process the robot was ready in three weeks and it created its tasks in 4 hours compared to 40 hours previously by the FTE (please see Figure 6). The company experience not only reduced costs, increased internal customer satisfaction, but also a way to keep the sensitive stuff like salaries outside of any interference with any FTE. 


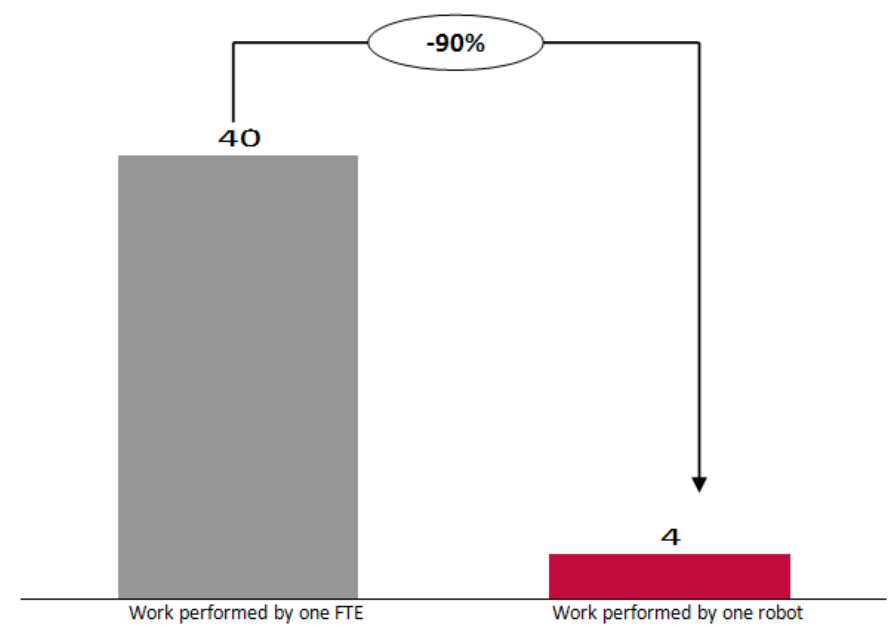

PICBE | 684

Figure 6. Work performed by an FTE vs. a robot

Source: Authors' own research.

\section{Introduction of RPA to an Oil\&Gas Company}

The finance department of an Oil\&Gas company wanted the introduction of RPA in order to free its FTEs from additional work and to let them focus on high-value added tasks (e.g. analyses, reports etc). The robot had to reconciliation the bank with the cash from the stations in the previous day. At the end, the accountant had to investigate further the differences. If there were none he or she would have lost more than 1 hours of its time only to make sure there is no difference.

Previously the work was allocated to seven accountants, each of this accountants had 13 stations and their work summed up 11 hours daily. After the RPA developed a robot to handle this task the time decreased to one hour as seen in the Figure 7:

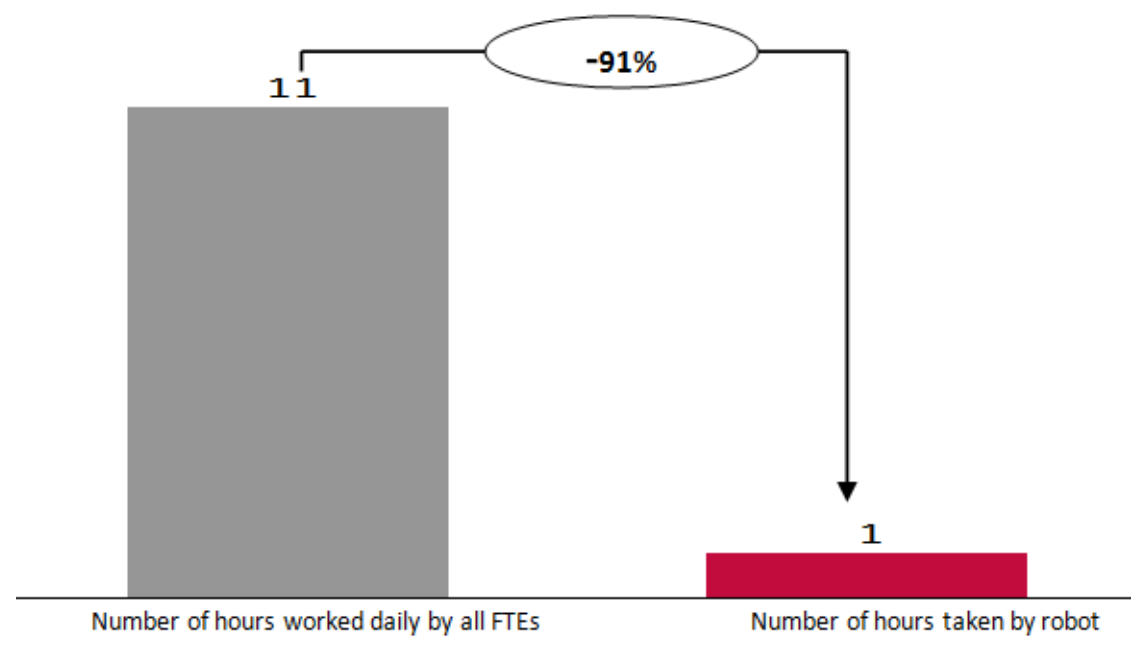

Figure 7. Work performed by an FTE vs. a robot

Source: Authors' own research.

\section{Conclusions}

Although there is still considered a "dummy" form of Artificial Intelligence, there are a lot of challenges and opportunities ahead: 
1) Governance - there is no regulation or at least not a set of governance that can regulate it, but as the Forrester Institute mentions "providers are responding: Connectivity monitoring; out-of-the-box version control apps; centrally controlled rollback capabilities; and testing procedures for application changes". These are just a few of the vendor's new solutions to this issue.

2) Process documentation and audit trails - once FTEs are replaced what a robot is doing can be known only by several people. But what happens when these people leave the organization? Who is picking up? A new process documentation form is being developed so at any moment every stakeholder can know exactly what the robots are doing. Moreover, although the robot has its logs, it can be also a solution to send those logs by email to a distribution list or to save it on a dedicated shared folder which can be accessed at any time by anyone interested and with proper access.

3) Machine Learning will come to RPA robots -The next 'big thing' in RPA is the integration of Artificial Intelligence solutions so that robots will understand when issues arise and will take decision(s) in order to solve it. For example, in a few years (3-5 years) a robot will be able to interpret a request sent by email or if a vendor asks the invoice's status the robot will be able to understand and to act accordingly, thus responding to the vendor. The AI solution will not be from introduced in the robot's code from external sources but rather will be something developed internally by the vendors providers, thus specifically designed for RPA technology.

4) Analytics will eventually come to RPA - Analytics it's a tool that can be used nowadays by humans, but which will eventually be used by robots alike.

5) New high-value added jobs - RPA can have an impact on approximately 30,000 FTEs in Romania, which means savings of more than 100 million Euros per year. Given the actual economic conditions with a population that is aging and decreasing, the actual situation can be a good step after all. People will be moved to high-value added tasks and those who will be let go can have the opportunity to learn new skills. Here are a list of industries and services that require a new of skills: Robot Process Automation, Artificial Intelligence, Augmenter Reality etc.

The next "big thing" is already here.

\section{References}

Le Clair, C., Cullen A., King M. (2017). The Forrester Wave ${ }^{\mathrm{TM}}$ : Robotic Process Automation, Q1 2017, Retrieved from http://reprints.forrester.com/\#/assets/2/661/'RES1311 82 '/reports.

Willcocks. L., Lacity, M., Craig, A. (2015). The IT Function and Robotic Process Automation, The Outsourcing Unit Working Research Paper Series, Paper 15/05. The London School of Economics and Political Science, London, UK.

Willcocks, L., Lacity, M. (2015). Robot Process Automation: The Next Transformation lever of Shared Services, The Outsourcing Unit Working Research Paper Series, Paper 15/10. The London School of Economics and Political Science, London, UK.

Outsourcing Industry Report. (2016). Retrieved from http://www.absl.ro/pressroom/reports. 
Pascari, M. (2016, 21 st September). Peste 60.000 de români lucrează în outsourcing, Retrieved from: http://www.zf.ro/profesii/peste-60-000-de-romani-lucreaza-inoutsourcing-15736590.

Robotic Process Automation: technology vendor state of the market report. (24th February 2017), Retrieved from http://www2.everestgrp.com/reportaction/EGR-2017-13-R2096/Marketing?searchTerms=rpa.

PICBE $\mid 686$ 